\title{
Analysis of Gene Expression in the Normal and Malignant Cerebellum
}

\author{
ROBERT J. WeChSLER-REYA \\ Department of Pharmacology and Cancer Biology, Duke University Medical Center, \\ Durham, North Carolina 27710
}

\begin{abstract}
The developing nervous system consists of a small number of multipotent precursors that undergo extensive proliferation to generate the neurons and glia that make up the adult brain. Elucidating the mechanisms that control the growth and differentiation of these cells is important not only for understanding normal neural development but also for understanding the etiology of central nervous system tumors. A particularly striking example of this is in the cerebellum. Recent studies have suggested that the Sonic hedgehog-Patched signaling pathway plays a critical role in regulating the proliferation of cerebellar granule cell precursors and is also a major target of mutation in the cerebellar tumor medulloblastoma. In light of these observations, identification of additional genes that control cerebellar growth and differentiation is likely to provide important insight into the basis of cerebellar tumors. Similarly, analysis of gene expression in medulloblastoma will no doubt shed light on previously unknown signaling pathways that regulate normal cerebellar development. The advent of high-throughput gene expression analysis techniques — such as adapter-tagged competitive polymerase chain reaction (ATAC-PCR), serial analysis of gene expression (SAGE), and DNA microarrays - makes identification of such genes faster and easier than ever before. This review summarizes recent studies of gene expression in the cerebellum and discusses the value of such approaches for understanding development and tumorigenesis in this tissue.
\end{abstract}

\section{Development of Cerebellar Granule Cells}

The cerebellum is required for motor coordination and has been implicated in a variety of cognitive and affective functions as well (Leiner et al., 1993; Altman and Bayer, 1997). These functions depend on precise interactions among at least five types of neurons (Altman and Bayer, 1997). The most abundant of these are the Purkinje cells, which carry signals from the cerebellum to other parts of the brain, and the granule cells, which regulate the activity of Purkinje cells. The murine cerebellum contains about $10^{8}$ granule cells, more than the total number of neurons in the rest of the brain. The critical importance of these cells is evident from mutant mice, in which loss of granule cells leads to severe ataxia (Mullen et al., 1997), and from patients with congenital granule cell degenera- 
tion, who have severe deficits in motor coordination, language use, and cognitive function (Pascual-Castroviejo et al., 1994).

Granule cell development has a number of unique features that distinguish it from other kinds of neurogenesis (Hatten and Heintz, 1995; Altman and Bayer, 1997). Whereas most neurons are born around the ventricles and then migrate outward toward the surface of the brain, granule cells are generated on the outside of the cerebellum and migrate inward (Figure 1). Granule cell precursors (GCPs) initially arise from a dorsal hindbrain structure called the rhombic lip (Alder et al., 1996; Alcantara et al., 2000; Wingate, 2001). During embryonic life, these cells leave the rhombic lip and stream across the outer surface of the cerebellum to form a region called the external germinal layer (EGL). After birth, cells in the EGL undergo extensive proliferation to generate a large pool of GCPs (Fujita et al., 1966; Mares et al., 1970). As new GCPs are generated, older cells move inward, then exit the cell cycle and differentiate (Fishell and Hatten, 1991; Komuro and Rakic, 1998). The differentiating cells extend axons that form synapses with Purkinje cells, then continue to migrate inward past the Purkinje cell bodies to their final destination, the internal granule layer (IGL). The waves of GCP proliferation and differentiation continue until about 3 weeks of age, at which time the EGL disappears and all GCPs complete their migration and differentiation into mature granule cells (Nicholson and Altman, 1972).

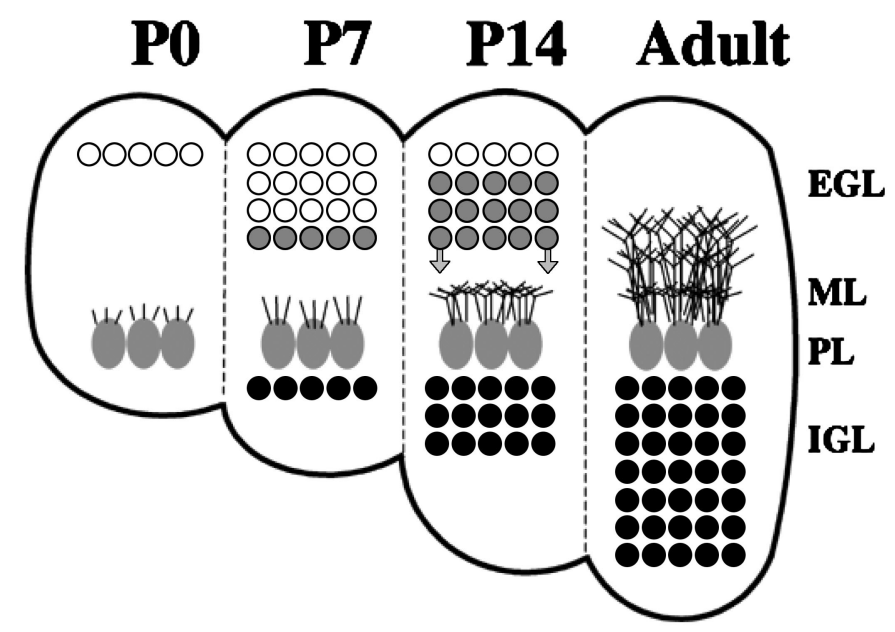

FIG. 1. Granule cell development. Granule cells are generated in the external germinal layer (EGL). After birth (P0), they proliferate to generate a large pool of precursors (white circles, $\mathrm{P} 0-\mathrm{P} 14)$. These cells move inward, exit the cell cycle, and differentiate (gray circles). They extend axons that synapse with Purkinje cells (gray ovals). Finally, cells migrate through the molecular layer (ML) and Purkinje cell layer (PL) to the internal granule layer (IGL). By adulthood, all precursors have become mature granule cells (black circles) and no EGL remains. 


\section{Control of Granule Cell Precursor Proliferation}

The observation that mutations in the Sonic hedgehog (Shh) signaling pathway result in cerebellar tumors in both mice and humans (Johnson et al., 1996; Goodrich et al., 1997; Raffel et al., 1997) suggested that this pathway might play a role in normal cerebellar growth and differentiation. Our own studies (Wechsler-Reya and Scott, 1999) and others (Dahmane and Ruiz-iAltaba, 1999; Wallace, 1999) demonstrated that Purkinje cells make Shh and that developing GCPs express all of the elements of the signaling pathway necessary to respond to it. Addition of recombinant Shh protein to GCPs in culture induces a 75- to 100-fold increase in thymidine incorporation within 3 days. Treatment of cerebellar slice cultures with Shh also causes a dramatic proliferative response and inhibits granule cell differentiation and migration. Finally, intracranial injection of Shh-blocking antibodies during early postnatal development leads to decreased proliferation of GCPs and a significant reduction in the thickness of the EGL. Together, these studies suggest that Shh is a critical regulator of GCP proliferation.

A number of factors present in the outer EGL enhance Shh-induced proliferation of GCPs. One of these is the extracellular matrix molecule, laminin (Wechsler-Reya and Scott, 1999; Pons et al., 2001). GCPs cultured on laminin show a 1.5- to 2-fold increase in Shh-induced proliferation, compared to cells cultured on other substrates. The chemokine stromal cell-derived factor-1 alpha $(\mathrm{SDF}-1 \alpha)$, produced by the pia mater that surrounds the EGL, induces GCP chemotaxis and also can synergize with Shh to enhance GCP proliferation in culture (Klein et al., 2001). Finally, heparan sulfate proteoglycans (HSPGs), which have been shown to be required for maximal hedgehog signaling in Drosophila, are present in the postnatal EGL and can increase Shh-induced proliferation of GCPs (Rubin et al., 2002). While none of these factors induces significant proliferation on its own, all may contribute to the proliferation of cells in the EGL.

Growth factors that act through receptor tyrosine kinases (RTKs) - epidermal growth factor (EGF), insulin-like growth factor (IGF-1), and basic fibroblast growth factor (bFGF) - have been reported to induce GCP proliferation (Gao et al., 1991; Tao et al., 1996; Ye et al., 1996; Lin and Bulleit, 1997). On their own, these factors cause a 2- to 4-fold increase in thymidine incorporation in cultured GCPs. Interestingly, however, they show no evidence of synergy with Shh; rather, EGF and IGF-1 cause a modest suppression of Shh-induced proliferation and bFGF reduces the Shh response by 90\% (Wechsler-Reya and Scott, 1999). This suggests that RTK-binding growth factors control proliferation through mechanisms distinct from the one used by Shh or that they act on distinct subsets of cerebellar cells. The fact that EGF, IGF-1, and bFGF also have potent effects on granule cell survival and differentiation (Hatten et al., 1988; Dudek et al., 
1997; Lin and Bulleit, 1997; Saffell et al., 1997; Gunn-Moore and Tavare, 1998; Liu and Kaczmarek, 1998) raises the possibility that these factors may control aspects of cerebellar development besides proliferation.

\section{Granule Cell-cycle Exit and Differentiation}

GCPs undergo extensive proliferation during the first 2-3 weeks after birth. But even as proliferation in the EGL reaches its peak, some GCPs are beginning to exit the cell cycle and differentiate into neurons. One possible explanation for this cell-cycle exit could be movement of cells away from Shh protein. For example, Shh might be present only in the outer EGL and, as cells move inward and away from the mitogenic signal, they might exit the cell cycle. Although this model has not been completely ruled out, the available evidence argues against it. Shh is made by Purkinje cells (Wechsler-Reya and Scott, 1999) and the protein has been detected throughout the EGL (Gritli-Linde et al., 2001; Pons et al., 2001). Moreover, Shh expression begins during embryonic life and persists into adulthood (Traiffort et al., 1999). Thus, termination of the proliferative response probably is not due to reduced exposure to Shh. Rather, it is likely to result from reduced responsiveness to Shh or conversion of the proliferative response into a differentiative one.

To date, three signals have been shown to overcome Shh-induced proliferation: the extracellular matrix molecule vitronectin $(\mathrm{VN})$, the protein kinase $\mathrm{A}$ (PKA) activator forskolin, and bFGF. In contrast to laminin, VN is found primarily in the inner EGL and granule cells in this region express alpha- $\mathrm{V}$ integrins, which can function as VN receptors (Pons et al., 2001; Wechsler-Reya, 2001). GCPs grown on VN show a $20 \%$ reduction in the proliferative response to Shh and increased $\beta$-tubulin expression and neurite outgrowth, compared to cells grown on other substrates. Growth on VN also causes increased phosphorylation of the transcription factor cAMP response element binding protein (CREB). CREB function appears to be required for VN's effects on neurite outgrowth (Pons et al., 2001). These observations suggest that VN may contribute to granule cell-cycle exit and differentiation.

Forskolin also can inhibit Shh-induced proliferation of GCPs (WechslerReya and Scott, 1999; Kenney and Rowitch, 2000). This is not surprising, since PKA activators can inhibit Shh responses in most tissues and in most species ( $\mathrm{Li}$ et al., 1995; Hammerschmidt et al., 1996; Ungar and Moon, 1996). Because forskolin is not a physiologic signal, there must be an endogenous factor that activates PKA for this to play a role in granule cell development. One good candidate for a PKA activator is pituitary adenylate cyclase activating polypeptide (PACAP) (Sherwood et al., 2000). PACAP is made by Purkinje cells (Nielsen et al., 1998; Skoglosa et al., 1999) and its receptors are expressed by GCPs in the outer EGL (Basille et al., 1993). To date, most studies of PACAP 
in the cerebellum have indicated that it increases proliferation of GCPs and promotes survival in the presence of various death-inducing stimuli (Vaudry et al., 1999,2002; Tabuchi et al., 2001). On the other hand, recent studies of neurons in the embryonic cortex and hindbrain indicate that PACAP can inhibit proliferation of those cells (Suh et al., 2001; Lelievre et al., 2002). Thus, PACAP might contribute to cell-cycle exit in the cerebellum as well.

Finally, bFGF is a potent inhibitor of proliferation, reducing the response to Shh by $90 \%$ (Wechsler-Reya and Scott, 1999). bFGF is made by cerebellar astrocytes and Purkinje cells (Hatten et al., 1988; Matsuda et al., 1994). At least two receptors capable of binding it (i.e., fibroblast growth factor (FGF)-1 and -4) are expressed in GCPs in the EGL (el-Husseini et al., 1994; Miyake et al., 1995; Ozawa et al., 1996; Meiri et al., 1998; Sleptsova-Friedrich et al., 2001). The observation that bFGF can prevent proliferation is consistent with a variety of studies demonstrating that it promotes granule cell differentiation and neurite outgrowth in vitro and in vivo (Williams et al., 1994; Hatten and Heintz, 1995; Saffell et al., 1997; Liu and Kaczmarek, 1998). However, as mentioned earlier, bFGF has been reported to induce proliferation of cerebellar cells in vitro and following subcutaneous injection (Tao et al., 1996; Cheng et al., 2001). In fact, we have observed that bFGF induces a small increase in thymidine incorporation in our cultures as well (Wechsler-Reya and Scott, 1999). One possible explanation for these observations is that the proliferative response to bFGF occurs in a subset of GCPs or in a distinct class of progenitor cells that are present in the postnatal cerebellum.

As granule cells differentiate, they extend axons and migrate inward, past the Purkinje cells, to the IGL. Bergmann glia are thought to provide a substrate for the migration (Edmondson and Hatten, 1987; Hatten, 1990; Komuro and Rakic, 1998) and therefore are a likely source of signals and guidance cues. Autocrine signaling by brain-derived neurotrophic factor (BDNF) is critical for initiation of migration from the EGL (Borghesani et al., 2002). Astrotactin, a granule cell surface molecule with EGF and fibronectin repeats, has been shown to be important for guiding granule cell migration (Edmondson et al., 1988; Zheng et al., 1996). Migration also has been shown to be regulated by N-methyl-Daspartate (NMDA) receptor activity and intracellular calcium concentration (Komuro and Rakic, 1993,1996).

\section{Gene Expression Analysis of the Developing Cerebellum}

The studies described herein have revealed a number of important factors that control proliferation and differentiation of granule cells. However, many important questions remain. For example, the molecular mechanisms by which Shh and other factors regulate growth of GCPs and the identity of the signals that control granule cell differentiation and migration in vivo are poorly understood. 
Moreover, the molecules that regulate growth and differentiation of other cell types in the developing cerebellum have not been identified. One important tool for identifying such molecules is gene expression analysis. By analyzing changes in gene expression during the course of cerebellar development, or by isolating specific cell types and comparing their gene expression under conditions of growth and differentiation, it may be possible to identify molecules that are important in normal growth and differentiation.

One of the first efforts at broad-based gene expression analysis in the cerebellum was carried out by Kuhar et al. (1993). These investigators raised polyclonal antisera against immature GCP and adsorbed them against PC12 cells (a cell line resembling peripheral neurons) and adult cerebellum to deplete non-GCP-specific antibodies. They then used the antisera to screen a cDNA expression library derived from GCPs, to identify GCP-specific genes. Using this approach, they cloned 39 unique cDNAs, 28 of which represented novel genes and showed tissue- and stage-specific expression. The majority were expressed at high levels early in development (i.e., postnatal days $0-10$ ), then downregulated by adulthood. Among these genes were at least four distinct expression patterns: 1) those that were localized in the outermost part of the EGL, where GCPs are proliferating; 2) those expressed in the inner EGL, where cells have exited the cell cycle and begun to differentiate; 3) genes expressed in the upper IGL, in postmitotic cells that had not yet completed migration; and 4) genes expressed in fully differentiated, postmigratory granule cells. These genes (some of which have now been cloned) (Miwa et al., 1999) not only provide valuable molecular markers for the stages of granule cell development but also represent a set of molecules that may play important functional roles in this process.

More-recent studies of gene expression in the cerebellum have taken advantage of high-throughput approaches using polymerase chain reaction (PCR) or microarrays. For example, Matoba and colleagues (2000a,b,c) generated cDNA libraries from cerebella of 4-day-old (P4), 12-day-old (P12), and 6-weekold (6W) mice and sequenced several thousand clones from each library. They then chose approximately 400 of these genes (i.e., those with the highest expression levels) and quantitated their expression levels using a technique known as adapter-tagged competitive PCR (ATAC-PCR) (Figure 2A). This involves isolating RNA from each sample (i.e., stage of development), converting it to cDNA, and then "tagging" one end of that cDNA with an adapter. For each sample, the cDNA is tagged with a different-sized adapter. The samples from each stage are mixed into a single tube and amplified by PCR using an adapter-specific primer and a gene-specific primer. After separation by gel electrophoresis, products from each sample can be discriminated based on their size (determined by the unique adapter). The amount of each fragment reflects the amount of original template. Relative expression levels in each sample can be deduced from their signal intensities. 

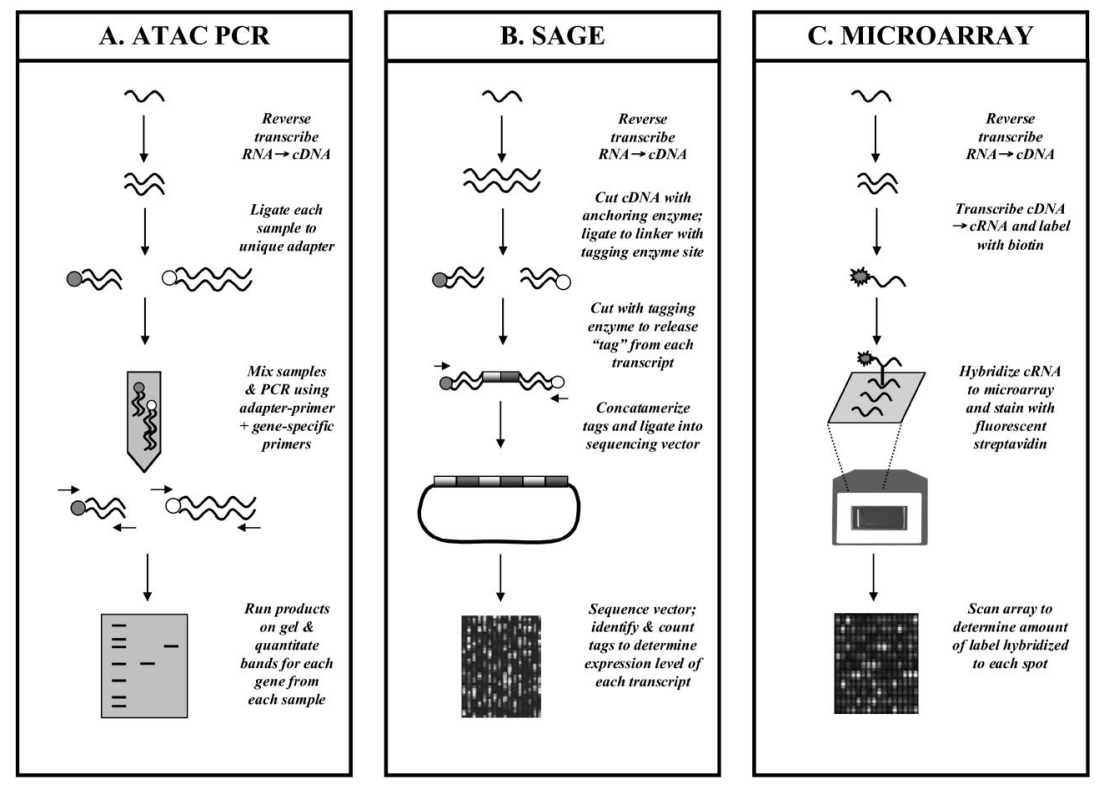

FIG. 2. Methods of genomic analysis. Procedures for adapter-tagged competitive polymerase chain reaction (ATAC-PCR), serial analysis of gene expression (SAGE), and Affymetrix GeneChip (Microarray) analysis are illustrated. [See text for details.]

Using this type of analysis, Matoba et al. (2000a,b) determined the expression of genes in the P4, P12, and $6 \mathrm{~W}$ samples and divided genes into groups based on expression profiles. Although a number of different cell types were represented, the differences in gene expression profiles correlated best with the development of granule cells, which are by far the most abundant cell type. Early in development (P4), when GCPs are undergoing rapid proliferation, the most abundant genes are those encoding ribosomal proteins, cytoskeletal proteins (e.g., tubulin, actin, thymosin $\beta 4$ ), and genes associated with proliferation (e.g., cdc2 kinase). Later in development (P12), when granule cells are engaged in axon extension and synapse formation, genes for mitochondrial activities (cytochrome c oxidase, mitochondrial proton/phosphate symporter), ion channels $(\mathrm{Na} / \mathrm{K}-\mathrm{ATPase})$, and markers of differentiated neurons (NeuroD, glutamate transporter, trkC) are elevated. Expression of many of these genes continues to increase during development. Finally, at 6 weeks, when differentiation of cerebellar neurons and glia is complete, elevated expression of synaptic proteins (e.g., soluble NSF (N-ethylmaleimide-sensitive factor) attachment protein SNAP25), neurotransmitter receptors (gamma aminobutyric acid receptors, GABA-Rs), and components of myelin (myelin basic protein and myelin proteolipid protein) are detected. 
In a subsequent study, Matoba et al. (2000c) expanded their analysis to include 1800 genes expressed over six different time points in cerebellar development: 2, 4, 8, and 12 days and 3 and 6 weeks. Their results again were clustered into 1) genes elevated early in development (e.g., 2, 4, and 8 days); 2) genes elevated later in development (e.g., 12 days, 3 weeks, 6 weeks); and 3) genes with complex expression patterns. About $80 \%$ of these could be classified based on function. The investigators looked for correlations between temporal expression profiles and functional categories and found that genes expressed early in development were enriched for those encoding cancer-related proteins (e.g., adenomatous polyposis coli (APC), c-erbA, abl, Krox24/Egr1) and ribosomal proteins. Other genes in this group were involved in RNA processing, cell adhesion/migration (e.g., VN, tenascin, neural cell adhesion molecule (NCAM), reelin), signaling, and transcription. In contrast, the genes expressed primarily in late postnatal development included those involved in protein transport, carbohydrate metabolism, "brain-specific functions," ion channels and transporters (ryanodine receptor 2, potassium channels, sodium channels, Na/K ATPases), lipid metabolism and neurotransmitter receptors (GABA-A receptors, NMDA receptors, AMPA (alpha-amino-3-hydroxy-5-methylisoxasole proprionic acid) receptors) and synapse components, and genes associated with mature oligodendrocytes (myelin basic protein, myelin proteolipid protein). Having found a number of known genes with documented functions in cerebellar development, the authors suggest that this approach may be used to identify novel genes that regulate granule cell growth and differentiation.

Gene expression in the postnatal cerebellum has also been studied by Kaltschmidt and Kaltschmidt (2001). These investigators initially were interested in the role of the transcription factor nuclear factor kappa B (NF- $\kappa \mathrm{B})$ in neuronal survival. They found that NF- $\kappa \mathrm{B}$ is expressed at high levels in the EGL before P7 and declines between P7 and P12. To identify signals that might account for this change in expression, the researchers used cDNA arrays to compare gene expression in P4 vs. P12 cerebellum. The arrays they used were commercial nylon membranes (macroarrays) spotted with 588 known cDNAs. mRNA from each developmental stage was labeled with ${ }^{32} \mathrm{P}$ and hybridized to a filter. Then, the level of hybridization was quantitated and compared using a phosphorimager. While most of the genes did not change, a small group $(\approx 40 / 588)$ was developmentally regulated; most of these increased between P4 and P12 but some decreased. Changes in expression were found among genes associated with proliferation and differentiation (c-myc, cyclin D3, cdc-like kinase 2, Id3), apoptosis and DNA repair (growth arrest and DNA damage (GADD45), topoisomerase II, TNF receptor-associated death domain (TRADD)), cell-signaling molecules (extracellular signal-regulated kinase (ERK)1, ERK3, jun kinase (JNK)3, mitogen-activated protein kinase (MAPK)2), cell adhesion (contactin 1, integrin $\beta 4, \mathrm{~N}$-cadherin, lymphocyte function-associated antigen 1 (LFA-1)), and 
growth factors and their receptors (insulin receptor, fibroblast growth factor receptor (FGFR)1, transforming growth factor (TGF)- $\beta 2$, macrophage colonystimulating factor (MCSF), fms-like tyrosine kinase (FLT-3) ligand).

The most highly induced gene during this period of development was the cytokine, TGF- $\beta 2$. The authors confirmed expression of TGF- $\beta 2$ in the EGL by in situ hybridization (ISH) and antibody staining and showed that expression levels increased significantly from P4 to P12. To test the functional effects of TGF- $\beta 2$, they added the factor to granule cells in culture and showed that it causes a rapid decrease in expression of the transcription factor, NF- $\kappa$ B. Since TGF- $\beta 2$ can promote granule cell apoptosis (de Luca et al., 1996) and NF- $\kappa \mathrm{B}$ can promote survival (Koulich et al., 2001; Piccioli et al., 2001), the authors suggest that increased expression of TGF- $\beta 2$ may play a role in the apoptosis that occurs during normal granule cell development in vivo (Wood et al., 1993).

Among the other genes whose expression increased from P4 to P12 were a number of elements of the FGF signaling pathway, including FGF receptor 1, MAPK2, ERK1, ERK3, and CREB2. As previously discussed, FGF signaling can promote granule cell-cycle exit and differentiation in vitro. The fact that multiple components of the FGF signaling pathway are coordinately regulated during a period of granule cell differentiation is consistent with the possibility that it plays this role in vivo as well. However, further studies of the effects of FGF signaling on granule cell development are necessary to validate this notion.

A more-comprehensive study of gene expression in the developing cerebellum was carried out by Zhao et al. (2002). These investigators initially examined gene induction in GCPs following Shh treatment, to identify target genes induced by this stimulus. They isolated cells from P4 -5 cerebellum and treated them with Shh protein for 3 or 24 hours, then harvested RNA for microarray analysis using Affymetrix GeneChips (Figure 2B). These arrays consist of thousands of short oligonucleotides (25-mers) conjugated to a solid matrix. Each gene is represented by $10-15$ oligonucleotides that match the coding sequence and a corresponding set of oligonucleotides that contain a one-base mismatch; the latter serve as controls for the specificity of hybridization. To analyze gene expression in a sample, RNA is isolated, converted to cDNA, and transcribed to generate biotin-labeled cRNA. This cRNA is hybridized to the Chip, incubated with a streptavidin-conjugated fluorescent dye, and scanned to detect the amount of fluorescence for each oligonucleotide. Analytical software is used to determine the expression levels of each gene and to compare expression between samples.

In their experiments, Zhao and colleagues found that $\approx 4 \%$ of the 13,000 genes on their microarrays were upregulated by Shh. Among these genes, $\approx 90 \%$ were involved in cell-cycle regulation (e.g., cyclins D1, B1, B2, A2, proliferating cell nuclear antigen (PCNA), E2F1, Ki67, cdc20). Other genes overexpressed in Shh-treated cells included transcription factors (Pax2, Math1, Gli2, N-myc) and genes involved in DNA replication and ribosome assembly. For comparison, the 
researchers also examined cells that were growth arrested and then treated with Shh, to identify genes that are induced by Shh in postmitotic granule cells. Although Shh did induce gene expression in these cells, the targets were largely distinct from those induced in GCPs.

To test whether the targets of Shh in proliferating GCPs were expressed in these cells in vivo, Zhao et al. examined expression of a number of genes by ISH. These studies revealed that 10/12 of the genes analyzed were expressed in EGL at postnatal day 1-7 and were downregulated by postnatal day 15 . Based on these findings, the authors proposed the concept of a temporal gene regulation profile (TRP) for the EGL: a set of genes that is temporally regulated in a pattern consistent with expression and function in proliferating GCPs in the EGL. In other words, genes whose expression was high from P1-P7 and low after P15 were likely to represent genes expressed in the EGL. If this concept could be validated, EGL-specific genes could be identified based solely on their expression profile during postnatal cerebellar development.

To test this hypothesis, the authors performed microarray analysis on whole cerebellum from P1-P30. In an initial test, they found that 10/12 genes that were known to be expressed in the EGL were expressed at high levels in P3-7 and downregulated from P15-30. To further validate this, they used microarray data to generate a list of genes whose developmental expression pattern fit that of the TRP-EGL, then examined their localization by ISH. The TRP-EGL profile correctly predicted EGL expression for more than $80 \%$ of the genes. These studies suggest that one can prospectively identify genes expressed in GCPs based on temporal changes in expression within the whole cerebellum.

These studies demonstrate that gene expression analysis can be a powerful tool for studying development and can provide valuable information about the genes that regulate cell growth and differentiation in a tissue. But when studying changes in gene expression during development - especially within an intact tissue - it is important to keep several issues in mind. First, changes in gene expression in the tissue may reflect changes in expression levels within a given cell type or changes in abundance of that cell type within the tissue. In fact, for much of cerebellar development, the abundance of granule cells tends to swamp out gene expression from most other cell types, including Purkinje cells, astrocytes, oligodendrocytes, and other interneurons. In order to learn about the genes that control development of these cells, it may be necessary to isolate them using laser capture microdissection (LCM) (Vincent et al., 2002) or antibodybased purification methods such as panning or fluorescence-activated cell sorting (Trotter and Schachner, 1989; Baptista et al., 1994; Catapano et al., 2001; Sawamoto et al., 2001). Alternatively, studies of mutant mice that have defects in particular cell types (Mullen et al., 1997) may shed light on the gene expression patterns important for particular aspects of cerebellar development. 
Regardless of the cell type or stage being studied, it is clear that gene expression analysis is only a first step towards understanding the molecular mechanisms of development. Once a profile of gene expression is identified, additional criteria must be used to narrow down the list of genes to a manageable number for further study. For example, one might focus on transcription factors or secreted proteins or genes that are likely to control cell adhesion or movement. Alternatively, it might be useful to perform additional screens to determine which of the expressed genes is dysregulated in a particular mutant mouse. Given a short list of genes, functional analysis - both in vitro and in vivo - will be necessary to understand how these genes contribute to a particular developmental process.

In addition to their importance in understanding cerebellar development, studies of gene expression in the normal cerebellum may have important implications for understanding the etiology of cerebellar tumors. For example, a number of genes expressed in the EGL and in GCPs stimulated with Shh (e.g., cyclin D1, N-myc, gli2) also have been shown to be expressed at high levels in some types of medulloblastoma (Pomeroy et al., 2002). This raises the possibility that other genes involved in regulating cerebellar growth, differentiation, and apoptosis might play a role in tumorigenesis.

\section{Medulloblastoma}

Medulloblastoma is a highly malignant tumor of the cerebellum. It occurs most commonly in children between 5 and 10 years of age and accounts for 20-30\% of all pediatric brain tumors (Schiffer, 1997; Zakhary et al., 2001). The disease usually is treated with a combination of surgery, radiation, and chemotherapy. While these approaches often are effective at shrinking the primary tumor, recurrence and metastasis are common and only $50 \%$ of patients survive for 5 years after diagnosis. Moreover, aggressive treatment of children with radiation and chemotherapy has been found to impair intellectual and physical development (Zakhary et al., 2001). New approaches to the diagnosis and treatment of medulloblastoma clearly are necessary and are most likely to come from a deeper understanding of the cellular and molecular basis of this disease.

Histologically, medulloblastoma often is divided into two major subtypes: classic and desmoplastic (Zakhary et al., 2001; Pomeroy et al., 2002). Classic medulloblastoma consists of small, round, densely packed cells that show little evidence of morphologic differentiation. Desmoplastic (or nodular) medulloblastomas contain regions of densely packed cells with extensive reticulin fibers surrounding "pale islands" of cells that are much less dense. The majority of medulloblastomas have the classic morphology; only $20-25 \%$ of tumors are considered desmoplastic. The cell of origin is not clear for either subtype but some studies suggest that desmoplastic tumors may arise from GCPs in the EGL, 
whereas classic tumors may derive from multipotent precursors that surround the ventricles and normally give rise to Purkinje cells, cerebellar interneurons, and glia (Katsetos and Burger, 1994; Buhren et al., 2000).

An important step in understanding the molecular basis of medulloblastoma came from studies of the Sonic hedgehog-Patched signaling pathway (Ingham and McMahon, 2001). As discussed, Shh is a secreted molecule that plays a critical role in embryonic development and is a major regulator of proliferation in the developing cerebellum (Dahmane and Ruiz-i-Altaba, 1999; WechslerReya and Scott, 1999). Patched (Ptc) is a transmembrane protein that functions as both a Shh receptor and an antagonist of Shh signaling. Several lines of evidence indicate that Shh-Ptc signaling is involved in medulloblastoma. First, the human patched gene has been identified as the locus mutated in Gorlin's syndrome, a disease characterized by skin tumors, craniofacial defects, and increased incidence of medulloblastoma (Hahn et al., 1996; Johnson et al., 1996). Second, many sporadic medulloblastomas (especially those of the desmoplastic type) have been found to harbor mutations in patched and other elements of the Shh pathway (Pietsch et al., 1997; Raffel et al., 1997; Lam et al., 1999; Taylor et al., 2002). Finally, mice in which the patched gene has been disrupted develop tumors that resemble medulloblastoma (Goodrich et al., 1997; Hahn et al., 2000).

Among the other genes associated with human medulloblastoma are components of the Wnt signaling pathway. Patients with Turcot's syndrome - which results from mutations in the APC gene - have a high incidence of colorectal cancers and brain tumors, especially medulloblastoma (Hamilton et al., 1995). About $4 \%$ of sporadic medulloblastomas have been shown to contain APC mutations (Huang et al., 2000). In addition, $8-15 \%$ have been reported to harbor activating mutations in $\beta$-catenin and $12 \%$ have mutations in Axin, a negative regulator of Wnt signaling (Zurawel et al., 1998; Eberhart et al., 2000; Huang et al., 2000; Dahmen et al., 2001). These findings suggest that a subset of medulloblastomas may result from activation of the Wnt pathway. Medulloblastomas also have been found to exhibit overexpression of the transcription factors $\mathrm{N}$-myc, c-myc, pax5, and zic and of the receptor tyrosine kinase ErbB2 (Garson et al., 1989; Bigner et al., 1990; Gilbertson et al., 1995; Kozmik et al., 1995; Yokota et al., 1996). Whether these genes contribute to the development or progression of medulloblastoma, or whether they simply represent markers of the transformed cell type, remains to be determined. Animals in which these genes are misexpressed will provide valuable insight into their role in the etiology of medulloblastoma.

One of the most important genes involved in medulloblastoma has yet to be identified. Of human medulloblastomas, $30-50 \%$ have a deletion or rearrangement of part of chromosome 17 (Cogen and McDonald, 1996; Bigner et al., 1997; Burnett et al., 1997). In most cases, the short arm (17p) is lost and head-to-head apposition of the long arms (17q) occurs, which is referred to as 
isochromosome $17 \mathrm{q}[\mathrm{i}(17 \mathrm{q})]$. This rearrangement frequently is detected in leukemias, lymphomas, and cancers of the stomach, colon, and cervix. The loss of $17 \mathrm{p}$ in a number of types of cancer suggests that at least one potent tumor suppressor gene is located there. Fine mapping of deletions from different tumors has narrowed the region of interest considerably. Most investigators now believe that the putative tumor suppressor is located at 17 p13.3, a region of $\approx 20$ known genes, including those encoding the lissencephaly-associated protein Lis1, the breakpoint cluster region (BCR)-related gene $A B R$, the Max-binding protein Mnt, and the transcription factor hypermethylated in cancer-1 (Hic1) (Koch et al., 1996; Steichen-Gersdorf et al., 1997; Sommer et al., 1999; Hoff et al., 2000; Rood et al., 2002). Although none of these genes has been linked definitively to the etiology of medulloblastoma, there is no question that when the chromosome 17 tumor suppressor is identified, it will provide important insight into the basis of cerebellar tumors as well as into normal cerebellar development.

\section{Gene Expression Profiling of Medulloblastoma}

In an effort to identify important genes involved in medulloblastoma, a number of investigators have begun to carry out gene expression analysis on primary tumor samples. One of the first efforts was performed by Michiels and colleagues (1999), who analyzed gene expression in a human medulloblastoma sample using serial analysis of gene expression (SAGE) (Figure 2C). SAGE is based on the principle that a sequence of $9-10$ nucleotides can be used to identify a transcript, if the position of these nucleotides within the transcript is known. A biotinylated oligo(dT) primer is used to synthesize cDNA from mRNA and, after digestion with a restriction enzyme, fragments are isolated from the $3^{\prime}$ end of each transcript. Fragments are ligated to linkers, then cleaved with a restriction enzyme to release a short sequence (i.e., 9-10 bp) from a defined region of the original cDNA (a "tag"). Tags are ligated together to form long concatamers, which are cloned and sequenced. Using this approach, one sequencing reaction can yield information about the number and distribution of many different tags. With the appropriate software, the sequence and position of the tag can be used to identify the gene from which each tag was derived. Moreover, the number of times each tag appears in the sequencing reaction is proportional to the abundance of that gene in the original sample. In this manner, SAGE gives a quantitative representation of gene expression in a sample.

For their study, Michiels and colleagues used SAGE to compare genes expressed in medulloblastoma to those expressed in 24.5-week fetal brain. They sequenced 10,000 tags from each sample and found about 6000 unique genes in each case. Among the most highly expressed genes in both samples were those encoding ribosomal proteins, consistent with the idea that both of these tissues contain highly proliferative (and protein-synthesizing) cells. Comparing the 
medulloblastoma and fetal brain samples, the investigators found 138 genes whose expression differed significantly. About half of these were known genes, including the transcription factors Zic1, Otx2, and Sox4; the secretory protein secretogranin; vascular endothelial growth factor (VEGF); and PCNA. Expression of Zic1 and Otx2 was examined by Northern blotting and found to be elevated in a number of independent medulloblastoma samples. The fact that both of these genes are expressed in the EGL lends support to the notion that at least some cases of medulloblastoma arise from GCPs.

A particularly elegant study of medulloblastoma gene expression was carried out by Pomeroy and colleagues (2002), who used Affymetrix GeneChips to compare medulloblastoma to other types of brain tumors. Since pathologists commonly have grouped medulloblastoma with primitive neuroectodermal tumors (PNETs) from other parts of the brain, the investigators were particularly interested in determining how similar these tumor types were. Studying the gene expression profiles of 42 brain tumors - including medulloblastoma, malignant glioma, atypical teratoid/rhabdoid tumors, and PNETs - they found that each of these tumor types was molecularly distinct. For example, gliomas expressed markers of astrocytic and oligodendrocytic cells (phosphoprotein-enriched in astrocytes-15 kDa (PEA15), SRY-related box2 (SOX2), peripheral myelin protein 2 (PMP2), Olig-2, S100, glial fibrillary acidic protein (GFAP)), whereas medulloblastomas expressed genes characteristic of cerebellar granule cells (e.g., Zic, neurological stem cell leukemia transcription factor (NSCL1)). Interestingly, although medulloblastoma and PNET look similar morphologically, they are molecularly distinct, with PNETs lacking Zic and NSCL1 and expressing high levels of nicotinic cholinergic receptor subunits and DNA polymerase delta 1 (POLD1).

Pomeroy et al. next addressed whether the two major subtypes of medulloblastoma described by pathologists - classic and desmoplastic - had distinct gene expression profiles. Consistent with the observation that desmoplastic tumors have a high incidence of Shh pathway mutations (Pietsch et al., 1997; Taylor et al., 2002), the researchers showed that desmoplastic tumors express high levels of Patched, Gli1, IGF-2, and N-myc, which have been identified as transcriptional targets of the Shh pathway (Goodrich et al., 1996; Hahn et al., 2000; Wetmore et al., 2000; Zhao et al., 2002). In addition, desmoplastic tumors express high levels of the antiapoptotic protein $\mathrm{Bcl} 2$ and ribosomal proteins, similar to those seen in normal EGL GCPs. In contrast, classic tumors show elevated levels of TGF $\beta 3$ and elements of its signaling pathway (Smad2, Smad5) and increased expression of the transcription factors distal-less homeobox gene 7 (DLX7), LIM-homeobox domain protein-2 (LH-2), and NeuroD3. These data clearly indicate that desmoplastic and classic medulloblastoma are not only histologically distinct but also have different gene expression profiles. 
In interpreting these differences, it is important to consider several possibilities. First, they may reflect differences in the cell type of origin or cellular composition of the tumors. For example, desmoplastic tumors may arise from GCPs, while classic tumors may arise from multipotent precursors in the ventricular zone. On the other hand, these tumors could arise from the same cell type. Differentially expressed genes might reflect activation of distinct signaling pathways that contribute to the etiology of tumor formation. Determining the functional significance of each of these genes is an important task for future study.

Independent of the role of these genes in the etiology of tumor formation, they may be significant as indicators of tumor prognosis and responsiveness to therapy. This is particularly important in medulloblastoma, since a significant percentage of patients may be cured by chemotherapy and radiation, while others are resistant and succumb to the disease. To address this possibility, Pomeroy et al. analyzed tumors from patients who had been treated and followed to determine the outcome of treatment. The data then were analyzed using a "supervised learning" scheme to determine which genes were best correlated with long-term survival. Among the best predictors of survival were genes associated with cerebellar differentiation (the vesicle coat protein $\beta$-NAP, the transcription factor NSCL1, the neurotrophin receptor TrkC, and sodium channels), and genes encoding extracellular matrix proteins (procollagen lysyl hydroxylase (PLOD), collagen type $\mathrm{V} \alpha 1$, elastin). On the other hand, poor prognosis was associated with increased expression of ribosomal proteins, the proliferation-associated genes B-myb and E2F5, and metabolic genes such as lactate dehydrogenase and cytochrome $\mathrm{C}$ oxidase. The multidrug resistance gene sorcin also was associated with poor outcome. Exactly how these genes might contribute to tumor progression (or resistance to therapy) remains to be determined. However, as a diagnostic tool, the ability to predict tumor outcome based on gene expression profile is likely to be extremely valuable.

A study of gene expression in metastatic medulloblastoma by MacDonald et al. (2001) may offer similar advantages. About one third of patients with medulloblastoma have metastatic disease at time of diagnosis and these patients are known to have a particularly poor outcome. In fact, disseminated disease is among the most powerful predictors of poor survival in medulloblastoma patients. To find molecular markers of metastatic medulloblastoma, these researchers used Affymetrix GeneChips to analyze gene expression in 10 metastatic $(\mathrm{M}+)$ and 13 nonmetastatic (M0) tumors. Of the 1992 genes on these arrays, 59 (3\%) showed significantly increased expression in $\mathrm{M}+$ tumors and 26 (1\%) showed significantly decreased expression. One prominent category of regulated genes included cell-surface and secreted proteins involved in adhesion and angiogenesis: $\alpha$-catenin; $\alpha$ - and $\beta$-integrins; secreted protein, acidic and rich in cysteine (SPARC); tissue inhibitor of matrix metalloproteinases (TIMP1); and 
TIE (a receptor for angiopoietin). Genes involved in growth factor receptor-rasMAP kinase signaling (platelet-derived growth factor receptor alpha (PDGFRA), FGF receptor 2, the adapter protein Src homology/collagen-related-1 (SHC1), the guanine nucleotide exchange factor (GEF2), rac-kinase $\beta$, protein kinase C-II $\beta$, JNK1) also were differentially expressed in metastatic vs. nonmetastatic tumors. Finally, metastatic tumors showed altered expression of transcription factors, including Hox A4 and A7 (which were overexpressed) and Nur77 and c-myb (which were expressed at lower levels). No differences were seen in expression of N-myc, patched, or ErbB2, which had previously been shown to be associated with medulloblastoma.

MacDonald and colleagues went on to develop an algorithm to predict whether a tumor was metastatic or nonmetastatic, based on its gene expression profile. This algorithm was able to predict tumor class with $72 \%$ accuracy and correctly categorized four new tumors. It predicted nonmetastatic tumors more accurately than metastatic ones, possibly because metastatic tumors are more heterogeneous with respect to cell type or gene expression profile. In addition to primary tumors, the authors analyzed the gene expression profile of several medulloblastoma cell lines. Although some of these lines could not be categorized, Daoy cells, a commonly used medulloblastoma cell line, clearly were categorized as metastatic.

The authors were particularly interested in elevated expression of PDGFRA and elements of the Ras-MAP kinase pathway in metastatic tumors, since PDGF has been shown to regulate angiogenesis, adhesion, and metastasis in other systems. They confirmed expression of PDGFRA protein in a panel of independent metastatic tumors as well as in Daoy cells. They then showed that soluble PDGFA causes activation of the Ras-MAPK pathway (including phosphorylation of MEK1, MEK2, and p42/p44 MAPK) in Daoy cells and enhances migration of these cells in culture. These effects could be prevented by PDGFRA-blocking antibodies and by MEK inhibitors. These findings suggested that inhibitors of the PDGFR or the Ras pathway could be used to treat metastatic medulloblastoma.

Together, these studies clearly demonstrate that gene expression profiles can be used to categorize tumors and to learn about their etiology. They also can be employed as diagnostic tools to predict prognosis and to choose appropriate treatment strategies. Finally, by highlighting signaling pathways that are dysregulated in tumors, gene expression information may yield new molecular targets or new approaches to treating tumors.

As with studies of normal development, there are a number of caveats to studying gene expression in intact tumors. First, tumors are heterogeneous and may contain a variety of cell types, including proliferating tumor cells, tumor cells that have undergone differentiation or apoptosis, blood and endothelial cells, and reactive astrocytes. Again, isolation of these cell types may yield important information about the molecular mechanisms of tumorigenesis. In 
addition, it is important to note that differences in gene expression between normal and tumor cells (or between different types of tumors) may reflect differences in the cell types represented, in genes that are important for the etiology of the tumor, or genes that are expressed as a consequence of tumor growth. Distinguishing between these possibilities may not be important if the goal is to identify prognostic or diagnostic markers but will be critical for understanding the underlying mechanisms of tumorigenesis.

\section{ACKNOWLEDGMENTS}

The authors thank Audra Carroll for designing the figures and Trudy Oliver for critical review of the manuscript.

\section{REFERENCES}

Alcantara S, Ruiz M, De Castro F, Soriano E, Sotelo C 2000 Netrin 1 acts as an attractive or as a repulsive cue for distinct migrating neurons during the development of the cerebellar system. Development 127:1359-1372

Alder J, Cho NK, Hatten ME 1996 Embryonic precursor cells from the rhombic lip are specified to a cerebellar granule neuron identity. Neuron 17:389-399

Altman J, Bayer SA 1997 Development of the Cerebellar System: In Relation to Its Evolution, Structure and Functions. Boca Raton, FL: CRC Press

Baptista CA, Hatten ME, Blazeski R, Mason CA 1994 Cell-cell interactions influence survival and differentiation of purified Purkinje cells in vitro. Neuron 12:243-260

Basille M, Gonzalez BJ, Leroux P, Jeandel L, Fournier A, Vaudry H 1993 Localization and characterization of PACAP receptors in the rat cerebellum during development: evidence for a stimulatory effect of PACAP on immature cerebellar granule cells. Neuroscience 57:329338

Bigner SH, Friedman HS, Vogelstein B, Oakes WJ, Bigner DD 1990 Amplification of the c-myc gene in human medulloblastoma cell lines and xenografts [published erratum appears in Cancer Res 1990 50(12):3809]. Cancer Res 50:2347-2350

Bigner SH, McLendon RE, Fuchs H, McKeever PE, Friedman HS 1997 Chromosomal characteristics of childhood brain tumors. Cancer Genet Cytogenet 97:125-134

Borghesani PR, Peyrin JM, Klein R, Rubin J, Carter AR, et al. 2002 BDNF stimulates migration of cerebellar granule cells. Development 129:1435-1442

Buhren J, Christoph AH, Buslei R, Albrecht S, Wiestler OD, Pietsch T 2000 Expression of the neurotrophin receptor p75NTR in medulloblastomas is correlated with distinct histological and clinical features: evidence for a medulloblastoma subtype derived from the external granule cell layer. J Neuropathol Exp Neurol 59:229-240

Burnett ME, White EC, Sih S, von Haken MS, Cogen PH 1997 Chromosome arm 17p deletion analysis reveals molecular genetic heterogeneity in supratentorial and infratentorial primitive neuroectodermal tumors of the central nervous system. Cancer Genet Cytogenet 97:25-31

Catapano LA, Arnold MW, Perez FA, Macklis JD 2001 Specific neurotrophic factors support the survival of cortical projection neurons at distinct stages of development. J Neurosci 21:88638872

Cheng Y, Tao Y, Black IB, DiCicco-Bloom E 2001 A single peripheral injection of basic fibroblast growth factor (bFGF) stimulates granule cell production and increases cerebellar growth in newborn rats. J Neurobiol 46:220-229 
Cogen PH, McDonald JD 1996 Tumor suppressor genes and medulloblastoma. J Neurooncol 29:103-112

Dahmane N, Ruiz-i-Altaba A 1999 Sonic hedgehog regulates the growth and patterning of the cerebellum. Development 126:3089-3100

Dahmen RP, Koch A, Denkhaus D, Tonn JC, Sorensen N, et al. 2001 Deletions of AXIN1, a component of the WNT/wingless pathway, in sporadic medulloblastomas. Cancer Res 61:7039-7043

de Luca A, Weller M, Fontana A 1996 TGF-beta-induced apoptosis of cerebellar granule neurons is prevented by depolarization. J Neurosci 16:4174-4185

Dudek H, Datta SR, Franke TF, Birnbaum MJ, Yao R, et al. 1997 Regulation of neuronal survival by the serine-threonine protein kinase Akt. Science 275:661-665

Eberhart CG, Tihan T, Burger PC 2000 Nuclear localization and mutation of beta-catenin in medulloblastomas. J Neuropathol Exp Neurol 59:333-337

Edmondson JC, Hatten ME 1987 Glial-guided granule neuron migration in vitro: a high-resolution time-lapse video microscopic study. J Neurosci 7:1928-1934

Edmondson JC, Liem RK, Kuster JE, Hatten ME 1988 Astrotactin: a novel neuronal cell surface antigen that mediates neuron-astroglial interactions in cerebellar microcultures. J Cell Biol 106:505-517

el-Husseini Ae-D, Paterson JA, Shiu RP 1994 Basic fibroblast growth factor (bFGF) and two of its receptors, FGFR1 and FGFR2: gene expression in the rat brain during postnatal development as determined by quantitative RT-PCR. Mol Cell Endocrinol 104:191-200

Fishell G, Hatten ME 1991 Astrotactin provides a receptor system for CNS neuronal migration. Development 113:755-765

Fujita S, Shimada M, Nakamura T 1966 H3-thymidine autoradiographic studies on the cell proliferation and differentiation in the external and the internal granular layers of the mouse cerebellum. J Comp Neurol 128:191-208

Gao WO, Heintz N, Hatten ME 1991 Cerebellar granule cell neurogenesis is regulated by cell-cell interactions in vitro. Neuron 6:705-715

Garson JA, Pemberton LF, Sheppard PW, Varndell IM, Coakham HB, Kemshead JT 1989 $\mathrm{N}$-myc gene expression and oncoprotein characterisation in medulloblastoma. Br J Cancer 59:889-894

Gilbertson RJ, Pearson AD, Perry RH, Jaros E, Kelly PJ 1995 Prognostic significance of the c-erbB-2 oncogene product in childhood medulloblastoma. Br J Cancer 71:473-477

Goodrich LV, Johnson RL, Milenkovic L, McMahon JA, Scott MP 1996 Conservation of the hedgehog/patched signaling pathway from flies to mice: induction of a mouse patched gene by Hedgehog. Genes Dev 10:301-312

Goodrich LV, Milenkovic L, Higgins KM, Scott MP 1997 Altered neural cell fates and medulloblastoma in mouse patched mutants. Science 277:1109-1113

Gritli-Linde A, Lewis P, McMahon AP, Linde A 2001 The whereabouts of a morphogen: direct evidence for short- and graded long-range activity of hedgehog signaling peptides. Dev Biol 236:364-386

Gunn-Moore FJ, Tavare JM 1998 Apoptosis of cerebellar granule cells induced by serum withdrawal, glutamate or beta-amyloid, is independent of Jun kinase or p38 mitogen activated protein kinase activation. Neurosci Lett 250:53-56

Hahn H, Wicking C, Zaphiropoulous PG, Gailani MR, Shanley S, et al. 1996 Mutations of the human homolog of Drosophila patched in the nevoid basal cell carcinoma syndrome. Cell 85:841-851

Hahn H, Wojnowski L, Specht K, Kappler R, Calzada-Wack J, et al. 2000 Patched target Igf2 is indispensable for the formation of medulloblastoma and rhabdomyosarcoma. J Biol Chem 275:28341-28344 
Hamilton SR, Liu B, Parsons RE, Papadopoulos N, Jen J, et al. 1995 The molecular basis of Turcot's syndrome. N Engl J Med 332:839-847

Hammerschmidt M, Bitgood MJ, McMahon AP 1996 Protein kinase A is a common negative regulator of Hedgehog signaling in the vertebrate embryo. Genes Dev 10:647-658

Hatten ME 1990 Riding the glial monorail: a common mechanism for glial-guided neuronal migration in different regions of the developing mammalian brain. Trends Neurosci 13:179184

Hatten ME, Heintz N 1995 Mechanisms of neural patterning and specification in the developing cerebellum. Annu Rev Neurosci 18:385-408

Hatten ME, Lynch M, Rydel RE, Sanchez J, Joseph-Silverstein J, et al. 1988 In vitro neurite extension by granule neurons is dependent upon astroglial-derived fibroblast growth factor. Dev Biol 125:280-289

Hoff C, Seranski P, Mollenhauer J, Korn B, Detzel T, et al. 2000 Physical and transcriptional mapping of the $17 \mathrm{p} 13.3$ region that is frequently deleted in human cancer. Genomics 70:26-33

Huang H, Mahler-Araujo BM, Sankila A, Chimelli L, Yonekawa Y, et al. 2000 APC mutations in sporadic medulloblastomas. Am J Pathol 156:433-437

Ingham PW, McMahon AP 2001 Hedgehog signaling in animal development: paradigms and principles. Genes Dev 15:3059-3087

Johnson RL, Rothman AL, Xie J, Goodrich LV, Bare JW, et al. 1996 Human homolog of patched, a candidate gene for the basal cell nevus syndrome. Science 272:1668-1671

Kaltschmidt B, Kaltschmidt C 2001 DNA array analysis of the developing rat cerebellum: transforming growth factor-beta2 inhibits constitutively activated NF-kappaB in granule neurons. Mech Dev 101:11-19

Katsetos CD, Burger PC 1994 Medulloblastoma. Semin Diagn Pathol 11:85-97

Kenney AM, Rowitch DH 2000 Sonic hedgehog promotes G(1) cyclin expression and sustained cell cycle progression in mammalian neuronal precursors. Mol Cell Biol 20:9055-9067

Klein RS, Rubin JB, Gibson HD, DeHaan EN, Alvarez-Hernandez X, et al. 2001 SDF-1 alpha induces chemotaxis and enhances Sonic hedgehog-induced proliferation of cerebellar granule cells. Development 128:1971-1981

Koch A, Tonn J, Kraus JA, Sorensen N, Albrecht NS, et al. 1996 Molecular analysis of the lissencephaly gene 1 (LIS-1) in medulloblastomas. Neuropathol Appl Neurobiol 22:233-242

Komuro H, Rakic P 1993 Modulation of neuronal migration by NMDA receptors. Science 260:95-97

Komuro H, Rakic P 1996 Intracellular Ca2 + fluctuations modulate the rate of neuronal migration. Neuron 17:275-285

Komuro H, Rakic P 1998 Distinct modes of neuronal migration in different domains of developing cerebellar cortex. J Neurosci 18:1478-1490

Koulich E, Nguyen T, Johnson K, Giardina C, D'Mello S 2001 NF-kappaB is involved in the survival of cerebellar granule neurons: association of IkappaBbeta [correction of Ikappabeta] phosphorylation with cell survival. J Neurochem 76:1188-1198

Kozmik Z, Sure U, Ruedi D, Busslinger M, Aguzzi A 1995 Deregulated expression of PAX5 in medulloblastoma. Proc Natl Acad Sci USA 92:5709-5713

Kuhar SG, Feng L, Vidan S, Ross ME, Hatten ME, Heintz N 1993 Changing patterns of gene expression define four stages of cerebellar granule neuron differentiation. Development 117:97-104

Lam CW, Xie J, To KF, Ng HK, Lee KC, et al. 1999 A frequent activated smoothened mutation in sporadic basal cell carcinomas. Oncogene 18:833-836

Leiner HC, Leiner AL, Dow RS 1993 Cognitive and language functions of the human cerebellum. Trends Neurosci 16:444-447 
Lelievre V, Hu Z, Byun JY, Ioffe Y, Waschek JA 2002 Fibroblast growth factor-2 converts PACAP growth action on embryonic hindbrain precursors from stimulation to inhibition. J Neurosci Res 67:566-573

Li W, Ohlmeyer JT, Lane ME, Kalderon D 1995 Function of protein kinase A in hedgehog signal transduction and Drosophila imaginal disc development. Cell 80:553-562

Lin X, Bulleit RF 1997 Insulin-like growth factor I (IGF-I) is a critical trophic factor for developing cerebellar granule cells. Brain Res Dev Brain Res 99:234-242

Liu SJ, Kaczmarek LK 1998 The expression of two splice variants of the Kv3.1 potassium channel gene is regulated by different signaling pathways. J Neurosci 18:2881-2890

MacDonald TJ, Brown KM, LaFleur B, Peterson K, Lawlor C, et al. 2001 Expression profiling of medulloblastoma: PDGFRA and the RAS/MAPK pathway as therapeutic targets for metastatic disease. Nat Genet 29:143-152

Mares V, Lodin Z, Srajer J 1970 The cellular kinetics of the developing mouse cerebellum. I. The generation cycle, growth fraction and rate of proliferation of the external granular layer. Brain Res 23:323-342

Matoba R, Kato K, Kurooka C, Maruyama C, Sakakibara Y, Matsubara K 2000a Correlation between gene functions and developmental expression patterns in the mouse cerebellum. Eur J Neurosci 12:1357-1371

Matoba R, Kato K, Saito S, Kurooka C, Maruyama C, et al. 2000b Gene expression in mouse cerebellum during its development. Gene 241:125-131

Matoba R, Saito S, Ueno N, Maruyama C, Matsubara K, Kato K 2000c Gene expression profiling of mouse postnatal cerebellar development. Physiol Genomics 4:155-164

Matsuda S, Ii Y, Desaki J, Yoshimura H, Okumura N, Sakanaka M 1994 Development of Purkinje cell bodies and processes with basic fibroblast growth factor-like immunoreactivity in the rat cerebellum. Neuroscience 59:651-662

Meiri KF, Saffell JL, Walsh FS, Doherty P 1998 Neurite outgrowth stimulated by neural cell adhesion molecules requires growth-associated protein-43 (GAP-43) function and is associated with GAP-43 phosphorylation in growth cones. J Neurosci 18:10429-10437

Michiels EM, Oussoren E, Van Groenigen M, Pauws E, Bossuyt PM, et al. 1999 Genes differentially expressed in medulloblastoma and fetal brain. Physiol Genomics 1:83-91

Miwa JM, Ibanez-Tallon I, Crabtree GW, Sanchez R, Sali A, et al. 1999 lynx1, an endogenous toxin-like modulator of nicotinic acetylcholine receptors in the mammalian CNS. Neuron 23:105-114

Miyake A, Minami M, Satoh M, Ohta M, Itoh N 1995 Transient expression of FGF receptor-4 mRNA in the rat cerebellum during postnatal development. Brain Res Mol Brain Res 31:95-100

Mullen RJ, Hamre KM, Goldowitz D 1997 Cerebellar mutant mice and chimeras revisited. Perspect Dev Neurobiol 5:43-55

Nicholson JL, Altman J 1972 The effects of early hypo- and hyperthyroidism on the development of rat cerebellar cortex. I. Cell proliferation and differentiation. Brain Res 44:13-23

Nielsen HS, Hannibal J, Fahrenkrug J 1998 Expression of pituitary adenylate cyclase activating polypeptide (PACAP) in the postnatal and adult rat cerebellar cortex. Neuroreport 9:26392642

Ozawa K, Uruno T, Miyakawa K, Seo M, Imamura T 1996 Expression of the fibroblast growth factor family and their receptor family genes during mouse brain development. Brain Res Mol Brain Res 41:279-288

Pascual-Castroviejo I, Gutierrez M, Morales C, Gonzalez-Mediero I, Martinez-Bermejo A, Pascual-Pascual SI 1994 Primary degeneration of the granular layer of the cerebellum. A study of 14 patients and review of the literature. Neuropediatrics 25:183-190 
Piccioli P, Porcile C, Stanzione S, Bisaglia M, Bajetto A, et al. 2001 Inhibition of nuclear factor-kappaB activation induces apoptosis in cerebellar granule cells. J Neurosci Res 66:1064-1073

Pietsch T, Waha A, Koch A, Kraus J, Albrecht S, et al. 1997 Medulloblastomas of the desmoplastic variant carry mutations of the human homologue of Drosophila patched. Cancer Res 57:2085-2088

Pomeroy SL, Tamayo P, Gaasenbeek M, Sturla LM, Angelo M, et al. 2002 Prediction of central nervous system embryonal tumour outcome based on gene expression. Nature 415:436-442

Pons S, Trejo JL, Martinez-Morales JR, Marti E 2001 Vitronectin regulates Sonic hedgehog activity during cerebellum development through CREB phosphorylation. Development 128: 1481-1492

Raffel C, Jenkins RB, Frederick L, Hebrink D, Alderete B, et al. 1997 Sporadic medulloblastomas contain PTCH mutations. Cancer Res 57:842-845

Rood BR, Zhang H, Weitman DM, Cogen PH 2002 Hypermethylation of HIC-1 and 17p allelic loss in medulloblastoma. Cancer Res 62:3794-3797

Rubin JB, Choi Y, Segal RA 2002 Cerebellar proteoglycans regulate sonic hedgehog responses during development. Development 129:2223-2232

Saffell JL, Williams EJ, Mason IJ, Walsh FS, Doherty P 1997 Expression of a dominant negative FGF receptor inhibits axonal growth and FGF receptor phosphorylation stimulated by CAMs. Neuron 18:231-242

Sawamoto K, Yamamoto A, Kawaguchi A, Yamaguchi M, Mori K, et al. 2001 Direct isolation of committed neuronal progenitor cells from transgenic mice coexpressing spectrally distinct fluorescent proteins regulated by stage-specific neural promoters. J Neurosci Res 65:220-227

Schiffer D 1997 Medulloblastoma. In: Brain Tumors: Biology, Pathology and Clinical References, chapter 15. Berlin: Springer-Verlag; 289-308

Sherwood NM, Krueckl SL, McRory JE 2000 The origin and function of the pituitary adenylate cyclase-activating polypeptide (PACAP)/glucagon superfamily. Endocr Rev 21:619-670

Skoglosa Y, Takei N, Lindholm D 1999 Distribution of pituitary adenylate cyclase activating polypeptide mRNA in the developing rat brain. Brain Res Mol Brain Res 65:1-13

Sleptsova-Friedrich I, Li Y, Emelyanov A, Ekker M, Korzh V, Ge R 2001 fgfr3 and regionalization of anterior neural tube in zebrafish. Mech Dev 102:213-217

Sommer A, Waha A, Tonn J, Sorensen N, Hurlin PJ, et al. 1999 Analysis of the Max-binding protein MNT in human medulloblastomas. Int J Cancer 82:810-816

Steichen-Gersdorf E, Baumgartner M, Kreczy A, Maier H, Fink FM 1997 Deletion mapping on chromosome 17p in medulloblastoma. Br J Cancer 76:1284-1287

Suh J, Lu N, Nicot A, Tatsuno I, DiCicco-Bloom E 2001 PACAP is an anti-mitogenic signal in developing cerebral cortex. Nat Neurosci 4:123-124

Tabuchi A, Koizumi M, Nakatsubo J, Yaguchi T, Tsuda M 2001 Involvement of endogenous PACAP expression in the activity-dependent survival of mouse cerebellar granule cells. Neurosci Res 39:85-93

Tao Y, Black IB, DiCicco-Bloom E 1996 Neurogenesis in neonatal rat brain is regulated by peripheral injection of basic fibroblast growth factor (bFGF). J Comp Neurol 376:653-663

Taylor MD, Liu L, Raffel C, Hui CC, Mainprize TG, et al. 2002 Mutations in SUFU predispose to medulloblastoma. Nat Genet 31:306-310

Traiffort E, Charytoniuk D, Watroba L, Faure H, Sales N, Ruat M 1999 Discrete localizations of hedgehog signalling components in the developing and adult rat nervous system. Eur J Neurosci 11:3199-3214

Trotter J, Schachner M 1989 Cells positive for the O4 surface antigen isolated by cell sorting are able to differentiate into astrocytes or oligodendrocytes. Brain Res Dev Brain Res 46:115-122 
Ungar AR, Moon RT 1996 Inhibition of protein kinase A phenocopies ectopic expression of hedgehog in the CNS of wild-type and cyclops mutant embryos. Dev Biol 178:186-191

Vaudry D, Gonzalez BJ, Basille M, Fournier A, Vaudry H 1999 Neurotrophic activity of pituitary adenylate cyclase-activating polypeptide on rat cerebellar cortex during development. Proc Natl Acad Sci USA 96: 9415-9420

Vaudry D, Rousselle C, Basille M, Falluel-Morel A, Pamantung TF, et al. 2002 Pituitary adenylate cyclase-activating polypeptide protects rat cerebellar granule neurons against ethanol-induced apoptotic cell death. Proc Natl Acad Sci USA 99:6398-6403

Vincent VA, DeVoss JJ, Ryan HS, Murphy GM Jr 2002 Analysis of neuronal gene expression with laser capture microdissection. J Neurosci Res 69:578-586

Wallace VA 1999 Purkinje-cell-derived Sonic hedgehog regulates granule neuron precursor cell proliferation in the developing mouse cerebellum. Curr Biol 9:445-448

Wechsler-Reya RJ 2001 Caught in the matrix: how vitronectin controls neuronal differentiation. Trends Neurosci 24:680-682

Wechsler-Reya RJ, Scott MP 1999 Control of neuronal precursor proliferation in the cerebellum by Sonic Hedgehog [see comments]. Neuron 22:103-114

Wetmore C, Eberhart DE, Curran T 2000 The normal patched allele is expressed in medulloblastomas from mice with heterozygous germ-line mutation of patched. Cancer Res 60:22392246

Williams EJ, Furness J, Walsh FS, Doherty P 1994 Activation of the FGF receptor underlies neurite outgrowth stimulated by L1, N-CAM, and N-cadherin. Neuron 13:583-594

Wingate RJ 2001 The rhombic lip and early cerebellar development. Curr Opin Neurobiol 11:82-88

Wood KA, Dipasquale B, Youle RJ 1993 In situ labeling of granule cells for apoptosis-associated DNA fragmentation reveals different mechanisms of cell loss in developing cerebellum. Neuron 11:621-632

Ye P, Xing Y, Dai Z, D'Ercole AJ 1996 In vivo actions of insulin-like growth factor-I (IGF-I) on cerebellum development in transgenic mice: evidence that IGF-I increases proliferation of granule cell progenitors. Brain Res Dev Brain Res 95:44-54

Yokota N, Aruga J, Takai S, Yamada K, Hamazaki M, et al. 1996 Predominant expression of human zic in cerebellar granule cell lineage and medulloblastoma. Cancer Res 56:377-383

Zakhary R, Keles GE, Aldape K, Berger MS 2001 Medulloblastoma and primitive neuroectodermal tumors. In: Kaye AH, Law ER, eds. Brain Tumors: An Encyclopedic Approach, chapter 31. London: Churchill Livingstone; 605-615

Zhao Q, Kho A, Kenney AM, Yuk Di DI, Kohane I, Rowitch DH 2002 Identification of genes expressed with temporal-spatial restriction to developing cerebellar neuron precursors by a functional genomic approach. Proc Natl Acad Sci USA 99:5704-5709

Zheng C, Heintz N, Hatten ME 1996 CNS gene encoding astrotactin, which supports neuronal migration along glial fibers. Science 272:417-419

Zurawel RH, Chiappa SA, Allen C, Raffel C 1998 Sporadic medulloblastomas contain oncogenic beta-catenin mutations. Cancer Res 58:896-899 